\title{
Stem cells and uterine leiomyomas: What is the evidence?
}

\author{
Márcia M Carneiro \\ Department of Obstetrics and Gynecology - Universidade Federal de Minas Gerais \\ Centro de Reprodução Humana Hospital Mater Dei - Belo Horizonte/MG
}

\begin{abstract}
Uterine leiomyomas, also known as uterine fibroids or uterine myomas, are the most common benign gynecologic tumors found in women of reproductive age. In spite of the numerous published studies evaluating the hormonal dependency, epidemiology, molecular biology, pathology, and genetics of leiomyomas, many questions remain unanswered. The remodeling of the uterus in response to hormonal stimuli and its return to a basal state may be related to adult stem/progenitor cells residing in the endometrial and myometrial layers. Recent published papers on stem cells and their paracrine interactions with more specialized cell populations within leiomyomas may help establish the missing link between the development of treatments designed to stop the growth of leiomyomas and therapies devised to eliminate them. Therefore, this study aimed to address the current paradigm regarding the evidence available on the role of stem/progenitor cells in the pathogenesis of uterine leiomyoma. Only a handful of studies involving humans have been published to date describing the presence of somatic stem cells (SSCs) in the myometrium and leiomyomas. No solid conclusion has been established thus far. Despite the fact that these studies strongly pointed to the vital role human leiomyoma stem cells might play in initiating the development of myomas, huge gaps still persist in the literature. Studies to identify putative myometrial and leiomyoma-specific markers might offer new possibilities for understanding the origin of these tumors and perhaps help develop new nonsurgical noninvasive treatments.
\end{abstract}

Keywords: Leiomyoma, fibroid, myoma, stem cells

\section{INTRODUCTION}

Uterine leiomyomas, also known as uterine fibroids or uterine myomas, are the most common gynecologic tumors found in women of reproductive age. Although benign, these tumors may be responsible for reproductive and gynecologic disorders ranging from infertility and pregnancy loss to pelvic pain and abnormal uterine bleeding, in addition to possibly accounting for 200,000 hysterectomies every year in the US alone (Parker, 2007; Bulun, 2013; Doherty et al., 2014)

Despite the numerous published studies evaluating the hormonal dependency, epidemiology, molecular biology, pathology, and genetics of fibroids, many questions concerning the etiology and the role of genetic or environmental factors on their pathogenesis remain unanswered (Flake et al., 2003; Sozen \& Arici, 2006; Blake, 2007; Ciarmela et al., 2011). Although the precise etiology and pathogenesis of myomas are unknown, advances have been made in understanding hormonal, genetic and growth factors, and the molecular biology of these benign tumors (Segars et al., 2014; Talylor et al., 2014).

The uterus displays fantastic plasticity in terms of tissue remodeling in mammals. It comprises the endometrium and an outer smooth muscle layer called myometrium. Major uterine morphological changes occur in response to cyclical hormonal cues from the ovary and from the embryo during pregnancy. The remodeling of the uterus in response to these stimuli and its return to a basal state may be related to adult stem (or progenitor) cells residing in the individual's endometrial and myometrial compartments (Sozen \& Arici, 2006; Blake, 2007). Furthermore, several conditions such as endometrial cancer, endometriosis, and leiomyomas, may be attributed to dysregulations of these same stem cells, or are derived from committed cells that acquire stem-like features (Garget, 2007; Ono et al., 2007; Teixeira et al., 2008; Garget et al., 2008; Hubbard et al., 2009; Gargett et al., 2012)

The myometrium undergoes significant changes in size and cell properties with the occurrence of specific physiological and pathological conditions such as leiomyomas (Blake, 2007). Each leiomyoma is thought to be a benign monoclonal tumor arising from a single transformed myometrial smooth muscle cell; however, it is not known what leiomyoma cell type is responsible for tumor growth (Sozen \& Arici, 2006; Blake, 2007; Ono et al., 2012). Recurrent genetic aberrations (trisomy of chromosome 12, deletions in 7q, and mutations affecting the mediator complex subunit 12 (MED12) or the high mobility group AThook 2 (HMGA2) have also been described in these uterine tumors. Such abnormalities as well as tumor stem cells are considered to play pivotal roles in the development and growth of leiomyomas (Blake et al., 2007; El-Gharib \& Elsobky 2010; Bulun, 2013)

Complete characterization of uterine stem/progenitor cells will improve our understanding of the mechanisms supporting physiological regeneration of the female reproductive tract (Garget, 2004). Recent published studies on stem cells and their paracrine interactions with more specialized cell populations within leiomyomas may help establish the missing link between the development of treatments to stop leiomyoma growth and therapies designed to eliminate them (Mas et al., 2014; Simon, 2014). In addition, such studies will enhance our understanding of uterine physiology and disease, though advances in the field have been rather slow (Simon, 2014). Thus, this review aimed to address the current paradigm regarding the evidence available on the role of stem/progenitor cells (SC) in the pathogenesis of uterine leiomyomas.

A review of the available literature was conducted using PubMed from 1966 through July 2015 using the following keywords: "leiomyoma", "fibroid", "myoma", "uterine stem cells", "myoma stem cells".

\section{Adult/Somatic stem cells}

Adult stem cells (also called somatic stem cells or tissue-specific stem cells) are rare, undifferentiated cells encountered in adult tissues and organs after embryonic development. These are a subset of cells residing in normal adult tissues that, through asymmetric division, retain their ability to self-renew while producing daughter cells that go on to differentiate and play a vital role in tissue regeneration and repair. Since they are very rare, they are extremely difficult to identify in tissues and lack distinguishing morphological features. As specific adult stem cell markers have not been successfully identified so far, these cells are thus defined by their functional properties: extraordinary self-renewal, high proliferative potential, and ability to differentiate into one or more lineages (Mas et 
al., 2014; Simon, 2014). In addition, a specific 'niche' is required for each type of adult stem cell to evoke stem cell activity (Eckfeldt et al., 2005; Gargett, 2007; Kuçi et al., 2009; Maruyama et al., 2013).

Other functional properties of adult stem cells include clonogenicity or colony forming unit (CFU) activity, Hoechst 33342 exclusion to identify side population (SP) cells, tissue reconstitution in vivo and DNA synthesis label (bromodeoxyuridine, BrdU) retention for identifying label-retaining cells (LRC). These functional analyses are necessary to single out adult stem cell activity while specific markers for these cells remain unidentified. Ongoing research, however, continues to look for markers of adult stem cells, although few are specific or defining. Adult stem cells play a vital role in tissue homeostasis by supplying replacement cells in routine cellular turnover and repairing injured tissues (Gargett, 2007; Ono et al., 2007; Teixeira et al., 2008).

Somatic stem cells responsible for the property of quiescence have been used to identify candidate stem cells through their ability to retain the nucleotide analog 5-bromo-2 -deoxyuridine (BrdU) (or 3H-thymidine) for long periods of time, whereas asymmetrically derived lineage-committed daughter cells dilute the BrdU label during rapid proliferation. These so-called label-retaining cells (LRCs) have been shown to correlate with somatic stem cells in various tissues, including the uterine endometrial epithelium and stroma, and have been used as a means of isolating somatic stem cells in tissues where stem cell surface markers have yet to be characterized (Chan \& Gargett, 2006; Gargett, 2010).

In the human female reproductive tract, tissue regeneration and growth occurs continuously in each menstrual cycle as well as during pregnancy. The endometrium must regenerate in each menstrual cycle and the uterus must also rapidly grow so as to accommodate the developing fetus. Uterine enlargement during pregnancy can be repeated multiple times throughout a woman's reproductive lifespan. Such cyclic physiologic pattern suggests that myometrial stem/progenitor cells may be present and play a role in myometrial function (Gargett, 2007; Ono et al., 2007; Maruyama et al., 2010;Maruyama et al., 2013).

\section{Stem cells in myomas}

In recent years, advances in stem cell biology have made it clear that most tissues are extremely plastic and renew through adult stem or progenitor cells. However, only a handful of studies have been performed on the role of adult somatic stem cells in female or male reproductive organs. Unfortunately, studies of adult stem cell biology in the uterus fall far behind other fields of stem cell research even though the uterus undergoes perhaps the most extensive proliferative changes and remodeling in adult mammals in comparison to other organs (Table 1) (Teixeira et al., 2008; Maruyama et al., 2010; Maruyama et al., 2013).

Myomas have been known to have a clonal origin but so far the initiating event remains unknown. Several theories have attempted to explain leiomyoma pathogenesis so far, and recently a role for uterine stem cells has been proposed. One possible explanation for the development of leiomyomas is the dysregulation of mesenchymal stem cell activity. However, there is little data supporting the existence of these cells in benign tumors such as uterine leiomyomas (Chang et al., 2010). Reports have demonstrated the existence of myometrial SCs by the identification of label-retaining cells in animal models (Szotek et al., 2007) and in the human myometrium (Ono et al., 2007) by the side population (SP) method.

The role of a putative stem cell factor (SCF) and its receptor in human myometrial tissue has been analyzed in an attempt to further the understanding of the role(s) of mast cells (MCs) in the uterus (Mori et al., 1997). Transcripts for SCF were found in myometrial tissues and myometrial smooth muscle cells. Additionally, enzyme-linked immunosorbent assays demonstrated that cultured myometrial cells produced SCF. Immunohistochemistry staining also revealed the existence of SCF receptors on the surface of myometrial MCs, thus indicating that MC proliferation and differentiation in the myometrium is regulated by SCF secretion from the uterine smooth muscle cells.

Ono et al. (2007) described a subset of myometrial cells isolated from non-pregnant human tissue characterized as side-population of myometrial cells (myoSP) by a distinct Hoechst dye efflux pattern. These myoSP cells lay in quiescence and lacked or expressed low levels of myometrial cell markers; however, they but could proliferate and ultimately differentiate into mature myometrial cells in vitro only under hypoxia. Despite the fact that the main population of myometrial cells (myoMP) displayed mature myometrial phenotypes before and after in vitro cultivation, only myoSP was able to generate functional human myometrial tissues efficiently when transplanted into the uteri of extremely immunodeficient mice. MyoSP cells were multipotent and could differentiate into osteocytes and adipocytes in vitro once the appropriate differentiation-inducing conditions were provided. Hence, myoSP displayed phenotypic and functional characteristics of myometrial stem cells. More studies on the area will enhance the understanding of myometrial physiology and the pathogenesis of myometrium-based diseases such as leiomyoma.

Chang et al. (2010) studied the differences between leiomyomas and normal myometrium tissue with regards to innate growth capacity by evaluating colony forming ability and mesenchymal stem cell markers based on CD90 expression and side-population (SP) cells as well as differentiation status by CD90 expression patterns after in vitro culture. Leiomyoma cells formed fewer mesenchymal stem cell colonies and displayed less Hoechst dye-excluding side-population (SP) cell activity versus cells isolated from normal myometrium tissue. Leiomyomas appeared more terminally differentiated whereas normal myometrium cells showed heterogeneous expression of CD90, a cell surface marker associated with the differentiation ability of uterine fibroblasts. Such findings suggest that the normal myometrium contains cells with stem/progenitor cell activity not seen in leiomyomas.

Galvez et al. (2010) used a simple non-invasive technique to identify a new cell type from mouse adult uterine biopsies (murine adult myometrial precursors or mAMPs). These cells were characterized by surface markers and were positive for CD31, CD34, CD44, CD117, Stro-1 and Sca-1. An analogous cell population (hAMPs) was also obtained in human biopsies. These cells showed ability to differentiate in vitro into a variety of mesodermal (smooth and skeletal muscle, osteoblasts and adipocytes) and epidermal lineages. Once injected into animal models with muscular disease, AMPs could produce new muscle fibers, and boost functional muscular recovery. In addition, these cells stimulated the regeneration of the uterine lining after wound healing, reconstructing the uterine muscular architecture. New vessels both in vitro and in vivo were also formed.

Zhou et al. (2011) proposed that human uterine myometrial stem cells exhibit specific phenotypic and functional attributes. Hypoxia appears to aberrantly activate estrogen-signaling pathways in certain myometrial stem cells, leading them to differentiate into leiomyoma cells. This process also shields the cells from physiological apoptosis or dedifferentiation. The authors concluded that hypoxia might be a key element in the pathogenesis of leiomyoma caused by aberrant 
Table 1 - Studies on the role of stem cells in leiomyoma pathology

\begin{tabular}{|c|c|c|c|}
\hline Author & Objective & Main results & Model \\
\hline $\begin{array}{l}\text { Mas et al., } \\
2015\end{array}$ & $\begin{array}{l}\text { Test the hypothesis that leiomyoma } \\
\text { development may be due to over- } \\
\text { expression of HMGA2 in myometrial } \\
\text { stem cells using in vitro and in vivo } \\
\text { approaches }\end{array}$ & $\begin{array}{l}\text { Overexpression of truncated/short HMGA2 form in myo- } \\
\text { metrial cells result in abnormal proliferation of the SSC } \\
\text { niche leading to the formation of leiomyoma-like tissue. }\end{array}$ & $\begin{array}{l}\text { Human } \\
\text { and } \\
\text { mice }\end{array}$ \\
\hline $\begin{array}{l}\text { Ono et al., } \\
2014\end{array}$ & $\begin{array}{l}\text { Identify cell surface markers to isolate } \\
\text { leiomyoma stem/progenitor cells. }\end{array}$ & $\begin{array}{l}\text { Significantly elevated CD } 49 \mathrm{~b} \text { and CD34 gene expression } \\
\text { in side population cells vs. main population cells }\end{array}$ & Human \\
\hline $\begin{array}{l}\text { Ono et al., } \\
2013\end{array}$ & $\begin{array}{l}\text { Demonstrate the critical paracrine role } \\
\text { of the wingless-type (WNT)/ } \beta \text {-catenin } \\
\text { pathway in estrogen/progesterone-de- } \\
\text { pendent tumorigenesis, involving LMSP } \\
\text { and differentiated myometrial or leio- } \\
\text { myoma cells. }\end{array}$ & $\begin{array}{l}\text { Wingless-type (WNT) acts as a paracrine signal from es- } \\
\text { trogen/progesterone receptor-rich mature cells activat- } \\
\text { ing the canonical } \beta \text {-catenin pathway in leiomyoma stem } \\
\text { cells, suggesting a paracrine role for the canonical WNT } \\
\text { pathway in the growth of leiomyomas. }\end{array}$ & Human \\
\hline $\begin{array}{l}\text { Mas et al., } \\
2012\end{array}$ & $\begin{array}{l}\text { Obtain human leiomyoma SP cells as } \\
\text { candidate tumor-initiating cells and es- } \\
\text { tablishment of two leiomyoma SP lines }\end{array}$ & $\begin{array}{l}\text { SP cells from human leiomyomas were isolated, identi- } \\
\text { fied, and characterized. Two leiomyoma SP cell lines with } \\
\text { a normal karyotype were established }\end{array}$ & $\begin{array}{l}\text { Human } \\
\text { and } \\
\text { mice }\end{array}$ \\
\hline $\begin{array}{l}\text { Ono et al., } \\
2012\end{array}$ & $\begin{array}{l}\text { Test the hypothesis that a distinct stem/ } \\
\text { reservoir cell-enriched population, des- } \\
\text { ignated as the leiomyoma-derived side } \\
\text { population (LMSP), is responsible for } \\
\text { cell proliferation and tumor growth }\end{array}$ & $\begin{array}{l}\text { LMSP, which show stem/reservoir cell characteristics, } \\
\text { are necessary for in vivo growth of leiomyoma xenograft } \\
\text { tumors. Decreased estrogen and progesterone receptor } \\
\text { levels in LMSP suggest an indirect paracrine effect of ste- } \\
\text { roid hormones on stem cells via the mature neighboring } \\
\text { cells. }\end{array}$ & $\begin{array}{l}\text { Human } \\
\text { and } \\
\text { mice }\end{array}$ \\
\hline $\begin{array}{l}\text { Chang et al., } \\
2010\end{array}$ & $\begin{array}{l}\text { Compare stem/progenitor cell charac- } \\
\text { teristics in both normal myometrium } \\
\text { and the corresponding leiomyoma of } \\
\text { patients undergoing hysterectomies }\end{array}$ & $\begin{array}{l}\text { Leiomyoma cells form fewer mesenchymal stem cell col- } \\
\text { onies and exhibit less Hoechst dye-excluding side popu- } \\
\text { lation (SP) activity, a function associated with progenitor } \\
\text { cells in other tissues, than cells isolated from normal } \\
\text { myometrium }\end{array}$ & Human \\
\hline $\begin{array}{l}\text { Ono et al., } \\
2007\end{array}$ & $\begin{array}{l}\text { Describe a subset of myometrial cells } \\
\text { isolated from the myometrium of } \\
\text { non-pregnant subjects that represents } \\
\text { the myometrial stem cell population }\end{array}$ & $\begin{array}{l}\text { When compared to the main population of myometrial } \\
\text { cells (myoMP), myoSP remained quiescent, underex- } \\
\text { pressed or lacked myometrial cell markers; they could } \\
\text { also proliferate and eventually differentiate into mature } \\
\text { myometrial cells in vitro only under low oxygen concen- } \\
\text { tration. myoSP produced functional human myometrial } \\
\text { tissues efficiently when transplanted into the uteri of se- } \\
\text { verely immunodeficient mice. myoSP were multipotent } \\
\text { and could differentiate into osteocytes and adipocytes } \\
\text { in vitro under appropriate differentiation-inducing con- } \\
\text { ditions }\end{array}$ & $\begin{array}{l}\text { Human } \\
\text { and } \\
\text { mice }\end{array}$ \\
\hline
\end{tabular}

estrogen pathway activation of myometrial stem cells.

Mas et al. (2012) tried to isolate and characterize the SP from human leiomyomas, analyzing its clonogenic activity under hypoxic conditions. Since no specific leiomyoma SC markers are available so far, the SP phenotype was used as a general approach to identify candidate leiomyoma SCs. Using these selection criteria, high proliferative clone formation and SP phenotype, the authors identified two human leiomyoma cell lines named LeioSP1 and LeioSP2. Microarray analysis detected 100 upregulated and 53 downregulated genes in leiomyoma SP compared to leiomyoma fragments. Leiomyoma SP cells also lacked typical muscle markers and hormone receptors indicating that they were not yet committed to a specific lineage. These cells showed in vitro and in vivo the ability to differentiate into mesenchymal lineage cell types and to form tissue-like leiomyoma in animal models. These results point to a possible role of stem cells as tumor initiating factors in the development of leiomyomas.

Ono et al. (2012) tested the hypothesis that a distinct stem/reservoir cell-enriched population, called the leiomyoma-derived side population (LMSP), could activate cell proliferation and tumor growth. Their results showed that leiomyomas have a lower percentage of SP cells when compared to normal myometrium tissue and that LMSP represent an immature or undifferentiated cell population. LMSP xenografts showed significantly increased proliferative activity in comparison to leiomyoma-derived main population (LMMP) xenografts. LMSP still requires a more thorough characterization so that the multiple mechanisms underlying the pathogenesis of leiomyoma are uncovered.

Recent in vitro data suggests that High Mobility Group A (HMGA), genes which encode DNA-binding nonhistone proteins that control cell growth by indirect regulation of the DNA transcription process, may be involved in the abnormal proliferation pattern seen in myomas. HMGA2 has been implicated in important functions related to cell growth and differentiation in the embryo development process. Disrupted expression in adult tissues plays a vital role in the growth of a variety of mesenchym-al tumors as a result of its oncogenic ability. Apparently, the overexpression of the truncated/short HMGA2 form in myometrial cells might result in abnormal proliferation of the SSC niche leading to the formation of leiomyoma-like tissue (Mas et al., 2015). 


\section{CONCLUSION}

Myoma development and progression depends on a number of variables: steroid hormones, growth factors, cytokines, chemokines, and extracellular matrix components. Such effect, however, depends on the triggering of an initial tumor-initiating event. Current evidence supports the role of putative stem/progenitor cells found in the human uterus as contributors to the onset of uterine disease such as uterine myomas.

To date, only a handful of studies involving humans have been published describing the presence of somatic stem cells (SSCs) in the myometrium and leiomyomas. However, none has conclusively established the role of such cells in the development of myomas. Although these studies strongly point to the existence of human leiomyoma SP cells possibly playing a role in the development of myomas, huge gaps remain in the literature (Simon, 2014). Studies to identify putative myometrial and leiomyoma specific markers might shed light on the mechanisms involved in the development of myomas and perhaps help develop new nonsurgical noninvasive approaches to treat patients with these tumors. Unfortunately, translating laboratory studies into clinical practice is still far from becoming a reality, as most studies performed with animal models have produced preliminary results at best.

\section{CONFLICT OF INTERESTS}

No conflict of interest have been declared.

\section{Corresponding author:}

Márcia Mendonça Carneiro

Department of Obstetrics and Gynecology

Universidade Federal de Minas Gerais

Belo Horizonte/MG - Brazil

E-mail: marciamc.ufmg@gmail.com

\section{REFERENCES}

Blake RE Leiomyomata uteri: hormonal and molecular determinants of growth. J Natl Med Assoc. 2007; 99:117084.

Bulun SE. Uterine fibroids. N Engl J Med. 2013; 369:134455.

Chan RW, Gargett CE. Identification of label-retaining cells in mouse endometrium. Stem Cells. 2006; 24: 1529-38.

Chang HL, Senaratne TN, Zhang L, Szotek PP, Stewart E, Dombkowski D, Preffer F, Donahoe PK, Teixeira J. Uterine leiomyomas exhibit fewer stem/progenitor cell characteristics when compared with corresponding normal myometrium. Reprod Sci. 2010; 17:158-67.

Ciarmela P, Islam MS, Reis FM, Gray PC, Bloise E, Petraglia F, Vale W, Castellucci M. Growth factors and myometrium: biological effects in uterine fibroid and possible clinical implications. Hum Reprod Update. 2011;17:772-90.

Doherty L, Mutlu L, Sinclair D, Taylor H. Uterine fibroids: clinical manifestations and contemporary management. Reprod Sci. 2014; 21:1067-92.

Eckfeldt CE, Mendenhall EM, Verfaillie CM. The molecular repertoire of the 'almighty' stem cell. Nat Rev Mol Cell Biol 2005;6:726-37.

El-Gharib MN, Elsobky ES. Cytogenetic aberrations and the development of uterine leiomyomata. J Obstet Gynaecol Res. 2010; 36:101-7.
Flake GP, Andersen J, Dixon D. Etiology and pathogenesis of uterine leiomyomas: a review. Environ Health Perspect 2003;111:1037-54.

Galvez BG, Martín NS, Salama-Cohen P, Lazcano JJ, Coronado MJ, Lamelas ML, Alvarez-Barrientes A, Eiró N, Vizoso $\mathrm{F}$, Rodríguez C. An adult myometrial pluripotential precursor that promotes healing of damaged muscular tissues. In Vivo. 2010; 24:431-41.

Gargett $\mathrm{CE}$, Nguyen HP, Ye L. Endometrial regeneration and endometrial stem/progenitor cells. Rev Endocr Metab Disord. 2012; 13: 235-51.

Gargett CE. Uterine stem cells: what is the evidence? Hum Reprod Update. 2007; 13:87-101.

Hubbard SA, Friel AM, Kumar B, Zhang L, Rueda BR, Gargett CE. Evidence for cancer stem cells in human endometrial carcinoma. Cancer Res. 2009; 69:8241-8.

Kuçi S, Kuçi Z, Latifi-Pupovci H, Niethammer D, Handgretinger R, Schumm M, Bruchelt G, Bader P, Klingebiel T. Adult stem cells as an alternative source of multipotential (pluripotential) cells in regenerative medicine. Curr Stem Cell Res Ther. 2009;4:107-17.

Maruyama $\mathrm{T}$, Masuda $\mathrm{H}$, Ono $\mathrm{M}$, Kajitani $\mathrm{T}$, Yoshimura $\mathrm{Y}$. Human uterine stem/progenitor cells: their possible role in uterine physiology and pathology. Reproduction. 2010; 140:11-22.

Maruyama T, Ono M, Yoshimura Y. Somatic stem cells in the myometrium and in myomas. Semin Reprod Med. $2013 ; 31: 77-81$.

Mas A, Cervelló I, Gil-Sanchis C, Faus A, Ferro J, Pellicer A, Simón C. Identification and characterization of the human leiomyoma side population as putative tumor-initiating cells. Fertil Steril. 2012; 98:741-51.

Mas A, Cervello I, Gil-Sanchis C, Simón C. Current understanding of somatic stem cells in leiomyoma formation. Fertil Steril. 2014; 102:613-20.

Mas A, Cervelló I, Fernández-Álvarez A, Faus A, Díaz A, Burgués $O$, Casado $M$, Simón $C$. Overexpression of the truncated form of High Mobility Group A proteins (HMGA2) in human myometrial cells induces leiomyoma-like tissue formation. Mol Hum Reprod. 2015 Apr;21(4):330-8.

Mori A, Nakayama K, Suzuki J, Nikaido T, Isobe M, Fujii S. Analysis of stem cell factor for mast cell proliferation in the human myometrium. Mol Hum Reprod. 1997 May;3(5):411-8.

Ono M, Bulun SE, Maruyama T. Tissue-specific stem cells in the myometrium and tumor-initiating cells in leiomyoma. Biol Reprod. 2014; 91:149.

Ono $\mathrm{M}$, Maruyama $\mathrm{T}$, Masuda $\mathrm{H}$, Kajitani $\mathrm{T}$, Nagashima $\mathrm{T}$, Arase $T$, Ito $M$, Ohta $K$, Uchida $H$, Asada $H$, Yoshimura $Y$, Okano $\mathrm{H}$, Matsuzaki Y. Side population in human uterine myometrium displays phenotypic and functional characteristics of myometrial stem cells. Proc Natl Acad Sci U S A. 2007; 104:18700-5.

Ono M, Qiang W, Serna VA, Yin P, Coon JS 5th, Navarro $A$, Monsivais D, Kakinuma T, Dyson M, Druschitz $S$, Unno K, Kurita T, Bulun SE. Role of stem cells in human 
uterine leiomyoma growth. PLoS One. 2012; 7:e36935.

Ono M, Yin P, Navarro A, Moravek MB, Coon JS 5th, Druschitz SA, Serna VA, Qiang W, Brooks DC, Malpani SS, Ma J, Ercan CM, Mittal N, Monsivais D, Dyson MT, Yemelyanov A, Maruyama T, Chakravarti D, Kim JJ, Kurita T, Gottardi CJ, Bulun SE. Paracrine activation of WNT/B-catenin pathway in uterine leiomyoma stem cells promotes tumor growth. Proc Natl Acad Sci U S A. 2013;110:17053-8.

Parker WH. Etiology, symptomatology, and diagnosis of uterine myomas. Fertil Steril. 2007; 87:725-36.

Segars JH, Parrott EC, Nagel JD, Guo XC, Gao X, Birnbaum LS, Pinn VW, Dixon D. Proceedings from the Third National Institutes of Health International Congress on Advances in Uterine Leiomyoma Research: comprehensive review, conference summary and future recommendations. Hum Reprod Update. 2014;20:309-33.
Simón C Introduction: Are we advancing in our scientific understanding and therapeutic improvement of uterine fibroids... or not? Fertil Steril. 2014 Sep;102(3):611-2.

Sozen I, Arici A. Cellular biology of myomas: interaction of sex steroids with cytokines and growth factors. Obstet Gynecol Clin North Am. 2006;33:41-58.

Szotek $\mathrm{P}$, Chang $\mathrm{HL}$, Zhang L, Preffer F, Dombkowski D, Donahoe PK, Teixeira J. Adult mouse myometrial label-retaining cells divide in response to gonadotropin stimulation. Stem Cells. 2007;25:1317-25.

Teixeira ], Rueda BR, Pru JK. Uterinestem cells. StemBook [Internet]. Cambridge (MA): Harvard Stem Cell Institute; 2008.

Zhou S, Yi T, Shen K, Zhang B, Huang F, Zhao X. Hypoxia: the driving force of uterine myometrial stem cells differentiation into leiomyoma cells. Med Hypotheses. 2011; 77: 985-6. 